\title{
Ramor 500 Zırh Çeliğinin Tozaltı Kaynak Yöntemi ile Birleştirilmesinde Tel İlerleme Hızının Kaynak Metalindeki Nüfuziyet Dengesinin İncelenmesi
}

\author{
Investigation of The Equilibrium of Permeate in The Welding Speed of The Wire Feeding \\ Speed in Joining Ramor 500 Armor Steel With Submerged Arc Welding Method
}

\author{
Semih TAŞKAYA*a, Ali Kaya GÜR ${ }^{\text {b }}$ \\ Fırat Üniversitesi, Teknoloji Fakültesi, Metalurji ve Malzeme Mühendisliği Bölümü, 23119, Elazı̆̆
}

• Geliş tarihi / Received: 23.05.2018 • Düzeltilerek geliş tarihi / Received in revised form: $22.01 .2019 \quad$ • Kabul tarihi / Accepted: 18.02 .2019

\begin{abstract}
$\ddot{O} z$
Ramor 500 zırh çeliği; 2-30 mm kalınlıklara sahip, 505-590 HV sertliklerde bulunan yüksek mukavemetli bir balistik koruma çeliği olarak sınıflandırılır. Çalışmada, Ramor 500 zırh çeliği malzeme çifti tozaltı kaynak yöntemiyle birleştirilmiştir. Kaynak işleminde kullanılan östenitik ilave tel $\mathrm{Cr}$, $\mathrm{Ni}$ ve $\mathrm{Mn}$ esaslıdır. Birleştirme işleminden sonra numuneler tahribatsız muayene yöntemlerinden biri olan, X-Ray kırınımı yöntemi ile radyografik muayene uygulanmıştır. Kaynak bölgesinin dikiş geometrileri ölçülmüş ve mikrosertlik analizleri yapılmıştır. Kaynaklı numunelerin çekme dayanımı testleri ile mekanik davranışları ve kırık yüzeylerin SEM-XRD analizleri ile kırılma tipi ve bileşik oluşumları incelenmiştir. Çalışma sonucunda, kaynak tel ilerleme hızı arttıkça kaynak dikiş formunun genişliği ve yüksekliği azalmakta ve çekme mukavemetleri ile \% gerinim artmaktadır. Birleşme ara yüzeydeki kırılma tipi, SEM-XRD sonuçlarından sünek kırılma olarak gözlemlenmiştir. Kaynak tel ilerleme hızına bağlı olarak mikrosertlik ölçümleri birbirine benzer sonuçlar vermiştir. Sertlik değerlerinin, ana malzeme ve ITAB'da azaldığı, kaynak metalinde ise yüksek artış gözlendiği incelenmiştir.
\end{abstract}

Anahtar kelimeler: Kaynak metali, Nüfuziyet Dengesi, Ramor 500, Tel İlerleme hızı, Tozaltı Kaynağı

\begin{abstract}
The Ramor 500 armor steel is classified as a high strength ballistic protection steel with 2-30 mm thicknesses and 505$590 \mathrm{HV}$ hardnesses. In the study, the Ramor 500 armor steel material pair was combined with a submerged welding method. The austenitic additive wire used in the welding process is based on $\mathrm{Cr}, \mathrm{Ni}$ and Mn. After the joining process, the specimens were subjected to radiographic examination by X-ray diffraction method, which is one of the nondestructive examination methods. Sewing geometry of weld zone was measured and micro hardness analysis was done. Tensile strength tests of welded specimens investigated the mechanical behaviors and fracture type and compound formations by SEM-XRD analysis of fractured surfaces. As the welding wire advance speed increases, the width and height of the weld seam form decreases and the tensile strength and \% strain increase. The fracture type at the interface was observed as ductile fracture from the SEM-XRD results. Microhardness measurements gave similar results depending on the feed rate of the welding wire. It has been investigated that hardness values decrease in main material and ITAB and increase in weld metal is observed.
\end{abstract}

Keywords: Weld metal, Permeate Equilibrium, Ramor 500, Wire progress rate, Submerged Welding

\footnotetext{
*a Semih TAŞKAYA; muh.semihtaskaya@gmail.com; Tel: (0537) 56029 63; orcid.org/0000-0003-1524-4537

b orcid.org/0000-0001-6077-1892
} 


\section{Giriş}

Ramor 500 zırh çelikleri yüksek hız darbelerine karşı üretilir. Ayrıca araç aydınlatması için otomotiv endüstrisinde kullanılır. Örneğin, beton bir karıştırıcıda yerleşik donanım, yapısal çelikten daha ince plaka ile Ramor 500 çelik kullanılarak üretilebilir. Böylece daha dinamik verimlilik ve yakıt tasarrufu sağlar (Memiş, 2016). Koruyucu malzeme seçimi ateşli silahlardan çıkan merminin, penetratörün ya da ateşli parçacığın türü, geometrisi ve penetrasyon kinetiğine göre yapılır. Belirtilen malzemeler arasında homojen olarak haddelenmiş zırh çelikleri (RHA, Rolled Homogeneous Armor) askeri platformlarda çok çeşitli, personel ve mühimmat taşıyan araçlarda koruyucu malzeme olarak kullanıldığı taktirde olumlu katkılar yapabilecek özelliklere sahiptir (Karagöz vd., 2008). Zırh çeliklerinin kullanıldığ araçlara örnek olarak zırhlı muharebe arac1 (ZMA), zırhlı taktik aracı, personel taşıyıcılar, Tow arac1, zirhlı havan arac1, istihkam manga arac1 ve komuta kontrol aracı verilebilir (Soykan vd., 2005). Zirh levhalarının kaynağında kullanılacak olan elektrodlar bileşimleri farklı da olsa, mutlaka bazik karakterde olmalıdır (TB92330-224-50/1, 1969). Bazik örtülü elektrodlar ile kaynak yaparken akım şiddeti, mümkün mertebe yüksek seçilmelidir (östenitik elektrodlar hariç). Yüksek akım şiddeti, elektrodun kolay tutuşmasını sağladığı gibi, kaynak banyosunun daha uzun süre sıvı halde kalmasını sağlar. Böylece, banyoda mevcut gazlar kolaylıkla çıkar ve dikişin gözeneksiz olması sağlanır (Dedehayır, 1985). Tozaltı kaynak yöntemi, 1933 yılında ABD'de geliştirilmiş ve 1937 yllından sonra da Avrupa'da uygulama alanına girmiştir. 2. Dünya Savaşı sırasında özellikle Almanya'da geniş çapta uygulanmıştır. Almanya'da LINDE tarafından Gektro-Linde-Rapid-Verfahren diye geliştirilen kaynak yöntemine k1saca Ellira-Verfahren adı verilmiştir. Kaynak maliyetini düşürmek, işin yapım süresini kısaltmak ve kaynakçı faktörünün dikişin kalitesine olan etkisini azaltmak için, kaynak prosesinde otomasyona gidilmiştir. Buradaki amaç, elektrot telini mekanik bir tertibat yardımı ile otomatik olarak sürekli ilerletip, ark bölgesine çok yakın bir yerden de akım vererek telin yüklenebileceği akım şiddetini artırmak ve böylece erime gücünü yükseltmektir (Kaluç, 2004). X-Ray tüpleri ve Gamma-Ray izotoplarıyla her çeşit kaynak dikişinin, döküm, dövme parçaların ve imalat sanayinin röntgenlerinin çekilmesi ve belgelenmesi mümkündür. Radyografi yönteminde nüfuz edici kısa boylu radyasyon dalgaları kullanılır. Kontrol edilecek olan malzeme içindeki yoğunluk farkları sayesinde hata tespitleri yapılır. Malzeme üzerine gönderilen 1şın genellikle film üzerine yansitılır. Malzeme içindeki yapı bozuklukları ve süreksizlikler nedeniyle farklı miktarda soğurulan ışınların yansımalarında farklı görüntüler oluşur. Gerçekte film üzerine yansıyan görüntü, malzemeden geçen 1şının yarattığ 1 gölge görüntüsüdür (Tekiz, 1984; Albayrak, 1997; URL-1, 2018; URL-2, 2018; TS EN 444, 1994; Y1ldız vd., 2017; Çalıgülü vd., 2016; Gür vd., 2016). Atapek (2011) yaptığı çalışmada, bor katkılı bir zırh çeliğinin fiziksel metalurjik esaslar doğrultusunda geliştirilmiş ve balistik performansını değerlendirmiştir. Isıl işlem koşullarına bağlı olarak, geliştirilen zırh çeliğinin sertlik, mukavemet, tokluk, aşınma gibi mekanik özelliklerinin ve korozyon direncinin dışında V50 balistik limiti ve yüksek çarpma hızlarındaki performansı araştırmıştır. Sonuçlarda, çarpma hızı arttıkça krater derinliği/krater uzunluğu oranı da arttığ1 gözlemlenmiştir. Maweja vd. (2006) yaptıkları çalışmada, hasar mekanizmalarını ve hem darbe bölgesinde hem de darbe bölgesine dik kesitte meydana gelen faz dönüşümlerini incelemek için çeşitli koşullardaki zırh çeliklerini $5,56 \mathrm{~mm}$ 'lik zırh delici mermilerle balistik olarak incelemişlerdir. Zırh malzemesinin içyapısının balistik başarımı doğrudan etkilediğini belirlemişlerdir. Gunaraj ve Murugan (1999), "Tepki Yüzey" methodunu kullanarak boruların tozaltı kaynağında, proses değişkenlerinin isının tesiri altında kalan bölge (ITAB) üzerindeki etkisini incelemişlerdir. Proses değişkenlerinin kaynak alanı üzerindeki birleşme yüzeyleri hem plakada hem de kaynak birleşme yüzeylerinde doğrudan ve dolaylı etkileri aynı bulunmuştur. Ayrı ayrı plaka eğimlerinin genellikle eşit olduğu da tespit edilmiştir. Wikle Iii vd. (2001), tozaltı kaynağında nüfuziyet derinliğinin kontrolü için kızılötesi sensör tekniği kullanmışlardır. Çalışmanın sonunda, kaynak proses parametrelerine ait geri beslemeli bir kontrol sistemi kullanarak, bu parametrelerin değişmesi durumunda kızılötesi sensör tekniği sayesinde nüfuziyet derinliğini sabit tutmay1 geliştirmişlerdir. Taşkaya vd. (2018), yaptıkları çalışmada, Ramor 500 zırh çeliği çiftinin tozaltı kaynağında birleştirilmesinde gerilimin etkisini incelemişlerdir. Çalışmanın sonunda, gerilime bağlı mikrosertlik sonuçlarının birbirine yakın olduğunu gözlemlemişlerdir. Sertliklerin ITAB bölgesinde azaldığını ve kaynak metalinde yüksek artış gösterdiğini tespit etmişlerdir.

Bu çalışmada ise, $3 \mathrm{~mm}$ kalınlığa sahip ve balistik koruma çeliği olarak sınıflandırılan Ramor 500 zırh çeliğinin toz altı kaynak yöntemi ile 
birleştirilmesi işlemi yapılmıştır. Tel ilerleme hızının kaynak metalindeki nüfuziyet dengesi, çekme mukavemeti testleri, X-Ray kırınımı yöntemi ile radyografik muayene, dikiş geometrisi ölçümleri, kaynaklı numunelerin kırık yüzeylerdeki SEM yapıları ile bileşik oluşumları ve mikrosertlik ölçümleri incelenmiştir.

\section{Materyal ve Metot}

Bu çalışmada, Tozaltı kaynak yöntemiyle Tablo 1 ve Tablo 2'de kimyasal ve mekanik özellikleri gösterilmiş olan $55 \times 65 \mathrm{~mm}$ uzunluk boyutunda, 3 $\mathrm{mm}$ kalınlığında piyasadan temin edilmiş olan Ramor 500 zırh çeliği malzemesi kullanılmıştır.
Deneysel çalışmada kullanılan, Ramor 500 zırh çeliği malzemesine uygun Ticari 1 firmasından temin edilen, Tablo 3'de kimyasal özellikleri verilmiş, Cr-Ni-Mn esasli SI-307 serili $2.4 \mathrm{~mm}$ çapında östenitik paslanmaz çelik tel kullanılmıştır. Kullanılan çelik tele özgün Ticari 2 firmasının önerdiği Ramor 500 zırh çeliği ile iyi karakterize olan, kaynakta koruyucu örtü görevinde olan alümina bazik karakterli $(\mathrm{AB})$ aglomera esaslı SF-104 serili kaynak tozu kullanılmıştır. Özellikle bu kaynak telinin tercih edilme sebebi, zırh çeliklerinin kimyasal bileşimlerinden dolayı, yüksek kaliteli kaynak dikişi ve derin bir nüfuziyet elde etmektir (Taşkaya vd., 2018).

Tablo 1. Ramor 500 zırh çeliğinin kimyasal bileşimi (URL-3, 2018).

\begin{tabular}{lllllllllll}
\hline \hline \multicolumn{1}{l}{ Kimyasal Bileşim (\% Oran) } \\
\hline \hline Malzeme & $\mathbf{C}$ & $\mathbf{S i}$ & $\mathbf{M n}$ & $\mathbf{P}$ & $\mathbf{S}$ & $\mathbf{C r}$ & $\mathbf{N i}$ & $\mathbf{M o}$ & $\mathbf{B}$ & $\mathbf{F e}$ \\
\hline Ramor 500 & 0.32 & 0.70 & 1.50 & 0.015 & 0.005 & 1.00 & 2.00 & 0.70 & 0.005 & Balans \\
\hline
\end{tabular}

Tablo 2. Ramor 500 zırh çeliğinin mekanik özellikleri (Yiğittürk, 2016; Taşkaya, 2017).

\begin{tabular}{llllll}
\hline \hline \multicolumn{2}{l}{ Mekanik Özellikler } & & & & \\
\hline \hline Malzeme & $\begin{array}{l}\text { Akma Değeri } \\
\text { Rp 0.2 (Mpa) }\end{array}$ & $\begin{array}{l}\text { Çekme Dayanımı } \\
\text { Rm (Mpa) }\end{array}$ & $\begin{array}{l}\text { Uzama } \\
\text { \% 5 }\end{array}$ & Sertlik (HV) & Darbe Gücü Charpy (V J) \\
\hline $\begin{array}{l}\text { Ramor } \\
\mathbf{5 0 0}\end{array}$ & 1450 & 1700 & 7 & $505-590$ & 20 \\
\hline
\end{tabular}

Tablo 3. Kaynak telinin kimyasal özellikleri (URL-4, 2018).

\begin{tabular}{|c|c|c|c|c|c|c|c|c|c|c|c|c|c|}
\hline \multicolumn{14}{|c|}{ Kimyasal Bileşim (\% Oran) } \\
\hline $\begin{array}{l}\text { Kaynak } \\
\text { Teli }\end{array}$ & $\begin{array}{l}\text { Tel Çapı } \\
(\mathrm{mm})\end{array}$ & $\mathbf{C}$ & $\mathbf{S i}$ & Mn & $\mathbf{P}$ & $\mathbf{S}$ & $\mathrm{Cr}$ & $\mathbf{N i}$ & Mo & $\mathrm{Cu}$ & $\mathbf{T i}$ & $\mathbf{N b}$ & $\mathrm{Fe}$ \\
\hline $\begin{array}{l}\text { SI-307 } \\
\end{array}$ & 2.40 & 0.066 & 0.4 & 6.85 & 0.011 & 0.003 & 19.32 & 8.52 & 0.06 & 0.07 & 0.01 & 0.01 & Balans \\
\hline
\end{tabular}

Tozaltı kaynak işlemi uygulanmadan önce, kaynak sırasında malzeme çiftlerinin birbirinden ayrılmaması için üst ve alt noktalarından elektrik ark ile puntalama işlemi yapılır ve sabitlenir. Birleştirme işleminde nüfuziyetin tam sağlanmasından dolayı, akım gücü $250 \mathrm{~A}^{\prime}$ de sabit tutulmuş, 20 volt geriliminde, $20,25,30 \mathrm{~cm} / \mathrm{dk}$ sabit tel ilerleme hılarında kaynak işlemi yapılmıştır. Numunelere ait kaynak işlem parametreleri Tablo 4'de verilmiştir. Kaynaklı birleştirmelerin kaynak işlemi öncesi ve sonrası resimleri Şekil 1'de, makro resimleri ise Şekil 2 'de gösterilmiştir.
Tablo 4. Kaynak işlem Parametreleri

\begin{tabular}{llll}
\hline \hline $\begin{array}{l}\text { Numune } \\
\text { Adı }\end{array}$ & $\begin{array}{l}\text { Kaynak } \\
\text { Gücü } \\
\text { (Amper) }\end{array}$ & $\begin{array}{l}\text { Gerilim } \\
\text { (Volt })\end{array}$ & $\begin{array}{l}\text { İlerleme } \\
\text { Hızı } \\
(\mathbf{c m} / \mathbf{d k})\end{array}$ \\
\hline N1 & & 20 \\
N2 & 250 & 25 & 25 \\
& & & 30 \\
\hline
\end{tabular}


Şekil 1. Ramor 500 malzeme çiftlerinin tozaltı kaynağı işlemi esnasindaki resimleri
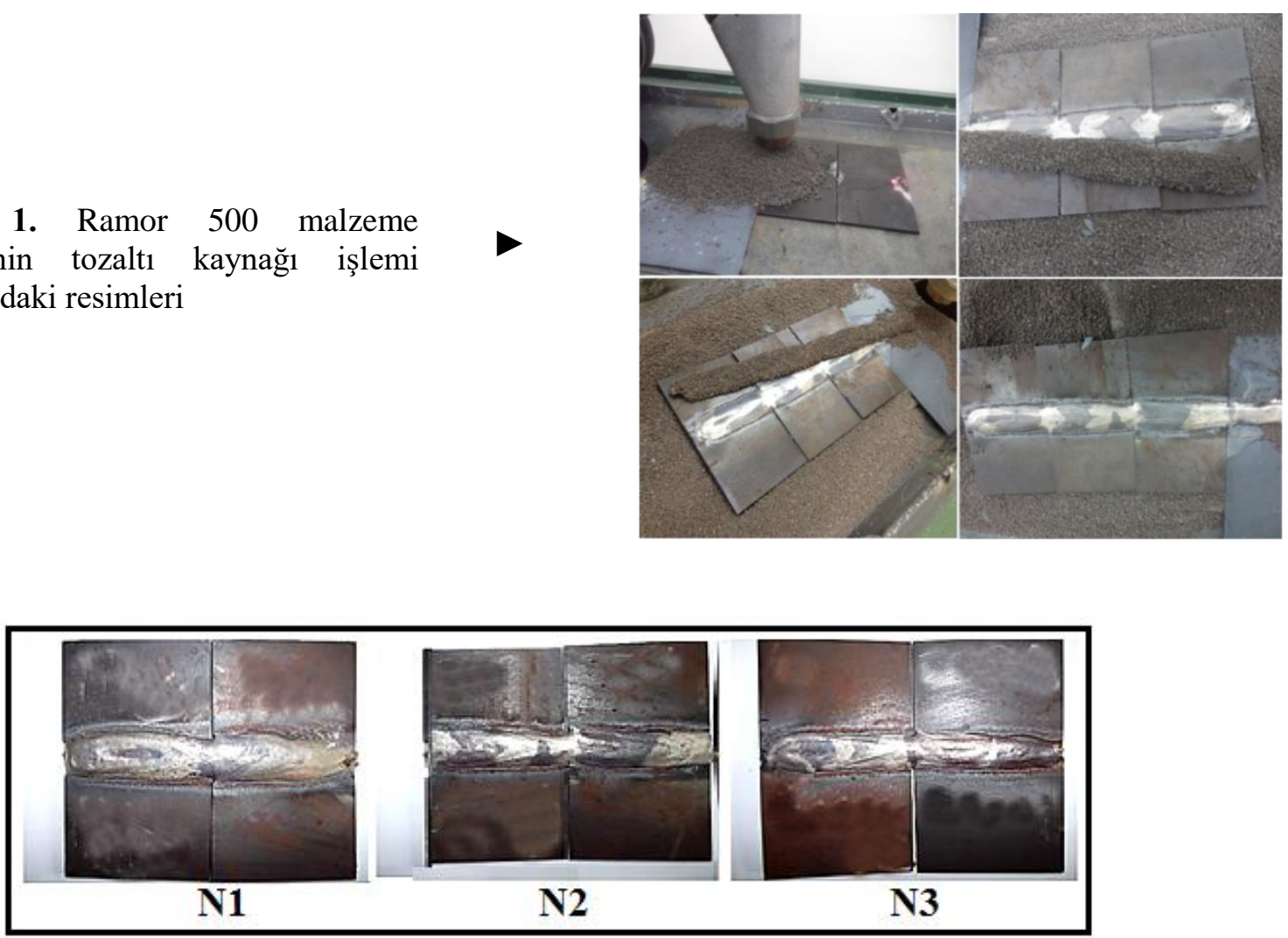

Şekil 2. Kaynaklı birleştirmelerin makro resimleri

Tozaltı kaynak işleminde, Ramor 500 zırh çeliği çiftinden aynı parametreler doğrultusunda 2 parça birleştirilmiştir. $\mathrm{Bu}$ birleştirmelerden en yüksek kalitede düzgün ve derin nüfuziyet sağlayan kaynak dikişleri seçilerek, kaynak numuneleri spiral ile birbirinden ayrılmıştır. Şekil 3'de kaynaklı birleştirmelerin ön ve arka yüz dikiş makro resimleri verilmiştir.
Tozaltı kaynak yöntemi ile birleştirilen kaynaklı numunelerin, iç yapı kaynak hatalarının tespit edilebilmesi için Şekil 4'de gösterilen tahribatsız muayene yöntemlerinden Radyografik muayene işlemi uygulanmıştır.

Kaynaklı numunelerin radyografik işılnama işleminden sonra elde edilen filmler banyo edilmiştir.

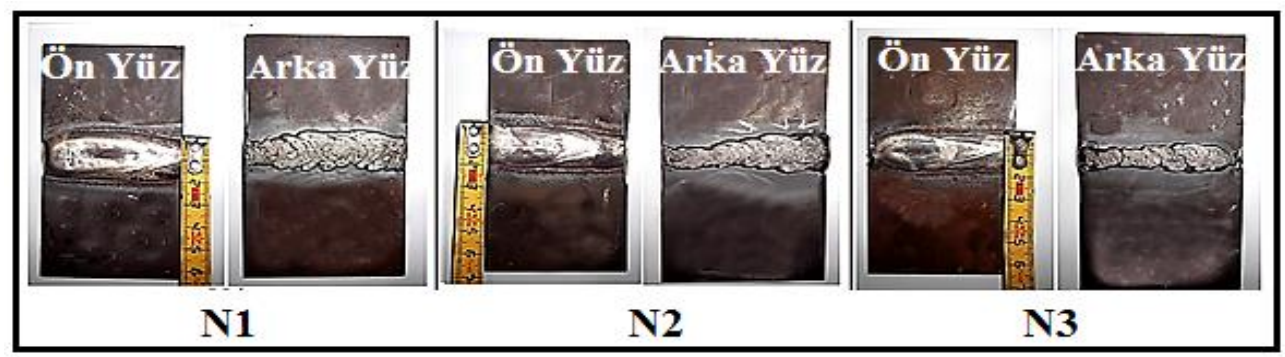

Şekil 3. Kaynaklı birleştirmelerin ön ve arka yüz dikiş makro resimleri

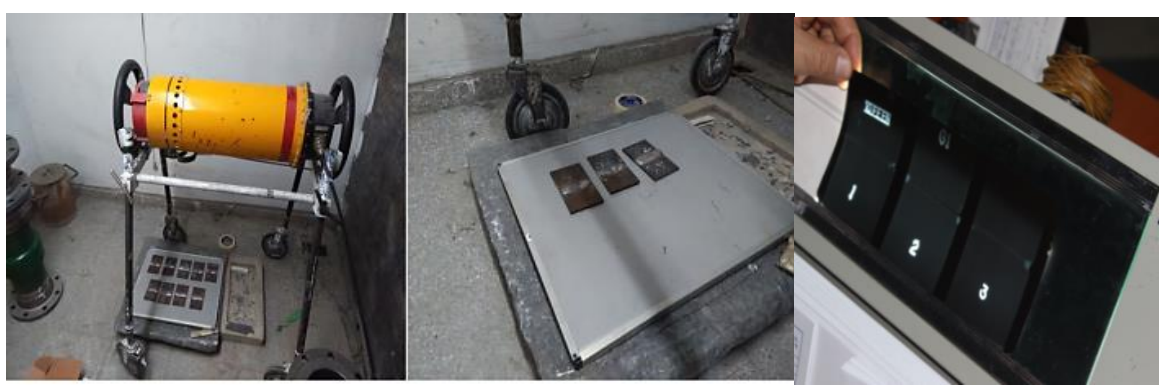

Şekil 4. Kaynaklı numunelerin radyografik muayene işlemi 


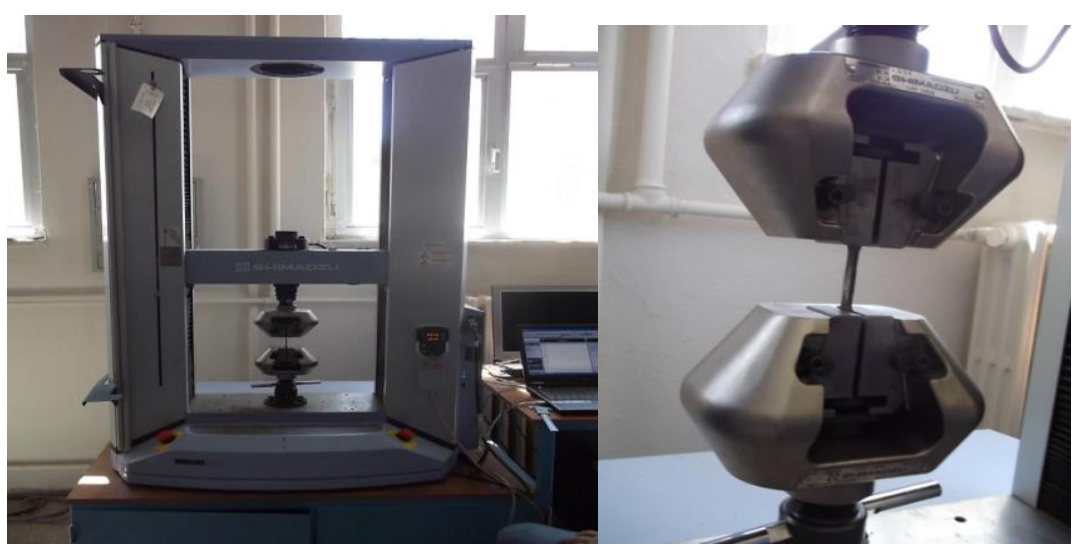

Şekil 5. Kaynaklı numunelerin çekme testi

Kaynaklı numunelerin yük taşıma kabiliyeti ile yükleme esnasındaki mekanik özelliklerini tespit etmek için çekme deneyi işlemi yapılmıştır (Şekil 5). Çekme deneyi, SHIMADZU AG-X marka 50 $\mathrm{kN}$ yük kapasitesine sahip çekme cihazında 1 mm/dk çekme hızında ve TSE 138 EN 10002-1 standardına uygun olarak yapılmıştır (Aydemir, 2013).

\section{Bulgular ve Tartışma}

250 A'de 25 volt geriliminde, 20, 25, $30 \mathrm{~cm} / \mathrm{dk}$ sabit tel ilerleme hızlarında birleştirilen N1, N2 ve N3 numunelerinde Şekil 6'da verilen radyografik muayenede uluslararası kaynak enstitüsünün yayınladığı ilkelere göre (Yıldız vd., 2017; Çalıgülü vd., 2016; Gür vd., 2016) N1 numunesinde kaynağın bitiş bölgesinde çok küçük oranda E (çatlak), N2 numunesinde A Kabul) raporu, N3 numunesinde ise kaynağın başlangıç ve bitiş bölgelerinde çok küçük oranda Dc (nufuziyet noksanlığı) hataları gözlemlenmiştir. Kaynağın başlangıç ve bitiş bölgelerinde çok küçük çatlak ve nüfuziyet kaynak hatalarının oluşu kaynaktan değil cürufun kaldırılması sırasında oluşması düşünülmektedir. Kaynak dikişi ve ITAB'da herhangi bir kaynak hatası görülmemiştir.

Şekil 7'de verilen kaynaklı birleştirmeler incelendiğinde, kaynak dikişinin birleştirilen Ramor 500 zırh çeliği çiftinin birleşme ara yüzeyinde oluştuğu gözlemlenmiştir. 250 sabit A'de makro resimlerden de anlaşılacağı gibi nüfuziyetin tam olduğu tespit edilmiştir.

Şekil 6. Kaynaklı numunelerin radyografik muayene rapor görüntüleri

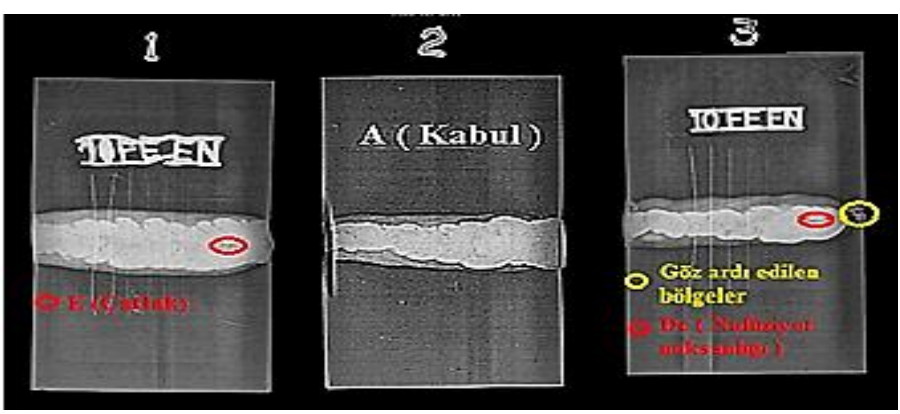

Şekil 7. Kaynaklı numunelerin dikiş geometri makro resimleri

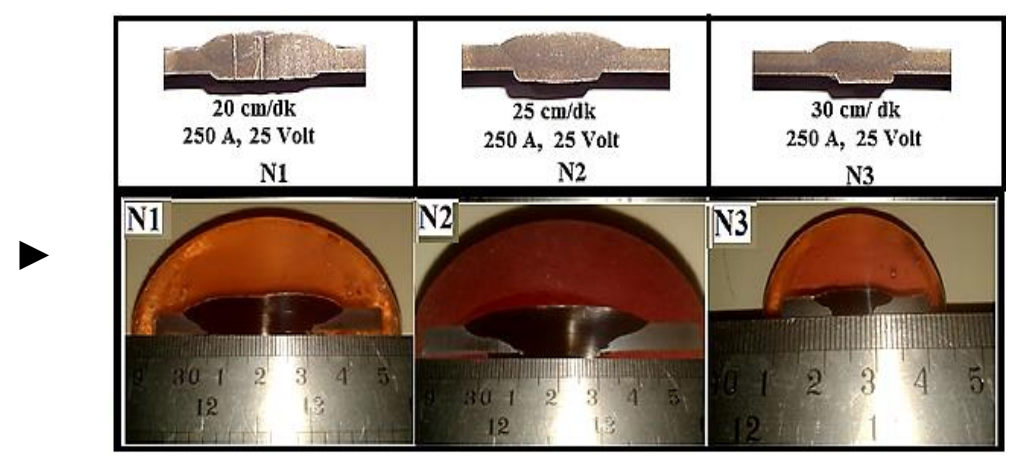


Tablo 5'de gösterilen Şekil 8'de grafiksel analizi verilen kaynaklı birleştirmelerin kaynak dikiş geometrisi üzerindeki etkisi kaynak tel ilerleme hızı arttıkça ters orantılı olarak kaynak genişlik ve yüksekliği azalmıştır (URL-5, 2018; Akkaş, 2006; Özakın, 2010). Kaynak hızı yükseldikçe, nüfuziyet ile dikiş genişliğinin azaldı ̆̆ görülür. Kaynak hızının artması, dikişlerin daha dikkatli kaynak edilmesini gerektirir. Gereğinden fazla kaynak hızı, ark üflemesini, gözeneği ve çatlağ 1 arttırır, dikişin şeklini bozar (Akkaş, 2006).

Tablo 5. Kaynak dikiş geometrisi ölçümleri

\begin{tabular}{lll}
\hline \hline \multicolumn{2}{l}{ Kaynak Geometrisi Ölçüm Değerleri } \\
\hline \hline Numuneler & $\begin{array}{l}\text { Dikiş Genişliği } \\
\text { (b), (mm) }\end{array}$ & $\begin{array}{l}\text { Dikiş } \\
\text { Yüksekliği } \\
\text { (h), (mm) }\end{array}$ \\
\hline N1 & 22.7 & 2.61 \\
\hline N2 & 20.25 & 2.6 \\
\hline N3 & 16.6 & 0.8 \\
\hline
\end{tabular}

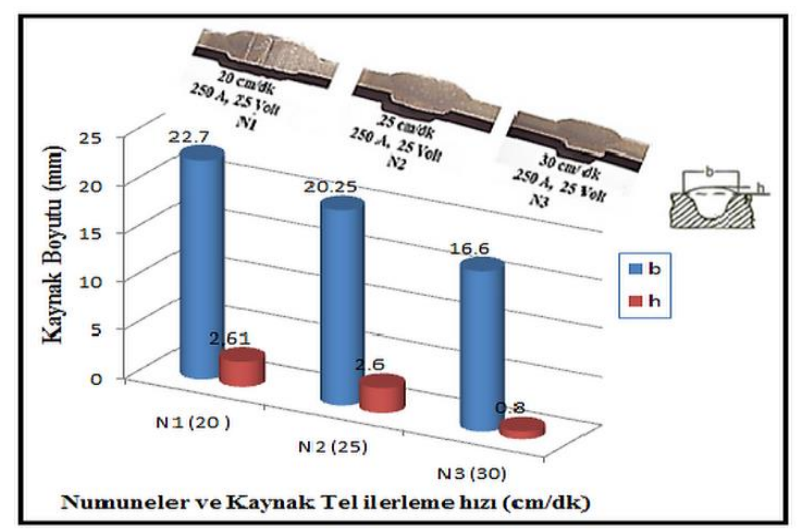

Şekil 8. Kaynaklı birleştirmelerin dikiş geometrisi grafiksel analizi

Şekil 9 ve 10 'da mikrosertlik ölçüm sonuçlarının tamamında elde edilen sertlik eğrilerine göre karşılaştırıldığında, kaynak dikişlerinin sertliğinde ana malzeme olan Ramor 500 çelik çiftlerine göre artış gözlemlenmiştir. İşlem görmemiş Ramor 500 çeliğinin mikrosertlik değeri $556 \mathrm{HV}$ olarak ölçülmüştür. Kaynak işlemi uygulandıktan sonra ana malzeme çiftinin olduğu bölgelerde, sertlikte çeliğin işlem görmemiş değerine göre azalma, ITAB bölgesinde sicaklığın etkisiyle tane yapılarında büyüme, sertlikte azalma ve sonra kaynak metaline doğru artış görülmüştür. Ana malzemede görülen sertliğin düşme nedeni, kaynak metalindeki dikiş genişliğinin fazla olmasından dolayı, ITAB bölgesindeki etkilenen yapıdan ana malzemeye de nüfus ettiği düşünülmektedir. Ramor 500 çeliğinde ITAB bölgesinde martenzitik yapının ferrite dönüşmesiyle ferrit taneleri büyür ve büyüme bu bölgede olumsuz etki yapacağından sertlikte düşmeye neden olur (Taşkaya vd., 2018; Durgutlu vd., 1999). Kaynak metalindeki sertlik yükselmesinin sebebinin kaynak havuzunun max. sıcaklığa eriştiği anda ilave östenitik esaslı paslanmaz çelik telin Cr'nin, Ramor 500 içindeki $\mathrm{C}$ ile oluşturduğu sert bileşiklerin yada ilave kaynak telindeki alaşım elementlerinin işlem sırasında oluşan 1sıdan dolayı meydana gelen yeni sert fazların varlığından olduğu düşünülmektedir. Çünkü östenitik paslanmaz çeliklerin kaynağında bu durum Schaffler diyagramı esas alınarak yapılan incelemelerde de martenzit oluşumu mikrosertlik değerlerinin yüksek çıkmasında önemli bir etken olarak göze çarpmaktadır (Yiğittürk, 2016). Ayrıca, kaynak metalindeki mikrosertlik değerlerinin yüksek çıkması; bu bölgede sertliği artırıcı ani soğuma sonucunda yoğun dentiritik yapının ortaya çımasından kaynaklanmaktadır. Şekil 11'de sandviç tabakada meydana gelen toplam mekanik gerilim dağılımları simulize edilmiştir. Burada meydana gelen gerilimler grafik analizlerle incelenmiştir.

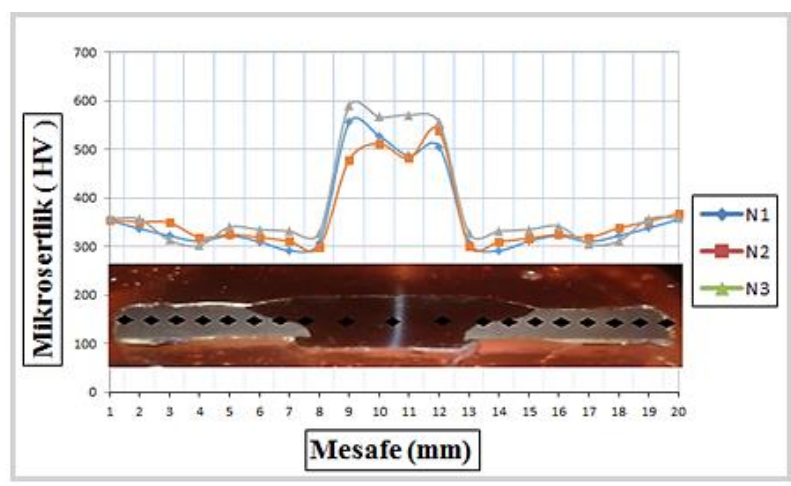

Şekil 9. Kaynakl1 birleştirmelerin yatay ekseninden alınan mikrosertlik ölçümleri

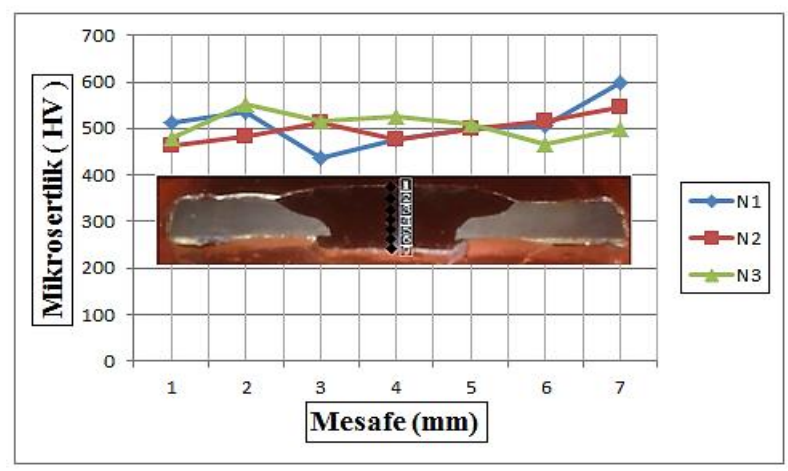

Şekil 10. Kaynaklı birleştirmelerin dikey ekseninden alınan mikrosertlik ölçümleri 
Kaynaklı birleştirmelere uygulanan çekme testi sonucunda kopan numunelerin Şekil 11-12 ve Tablo 6 ölçüm değerleri incelendiğinde boyun vermeden kırılma meydana geldiği gözlemlenmiştir. Dolayısıyla bu haliyle incelenen çelik malzemenin boyun vermemiş olması her ne kadar gevrek malzemeymiş gibi görünse de, Şekil 11 'deki makro görüntüler incelendiğinde kopma yüzeylerinde koni-çanak yapılarını andıran görüntüler vardır. Ayrıca kopma yüzeyleri tam düz değil tırtırlı olacak şekilde kopmuştur. Yani mevcut haliyle de bu malzeme çiftlerinin sünek kırılma mekanizmasıyla koptuklarını söyleyebiliriz. Bunun nedeni kaynak dikişinin eriştiği mukavemet değerinin östenitik esaslı paslanmaz çelik telin mukavemet değerinden yüksek oluşundan kaynaklanmaktadır. Çünkü sünek kırılma yüksek orandaki plastik deformasyon sonrasinda meydana gelir ve malzeme kırık yüzeyinde koni çanak şeklinde bir kırık yüzey oluşumu kendini gösterir.

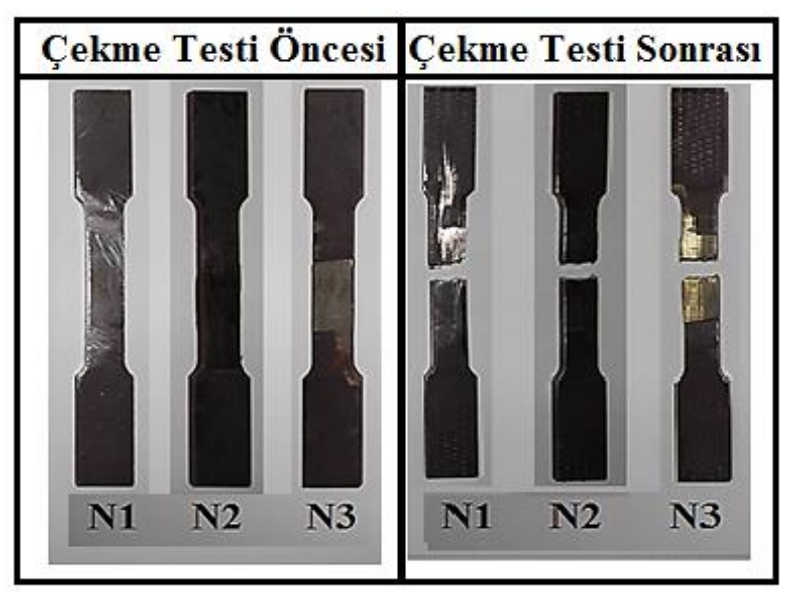

Şekil 11. Kaynaklı birleştirmelerin çekme testi öncesi ve sonrası makro resimleri
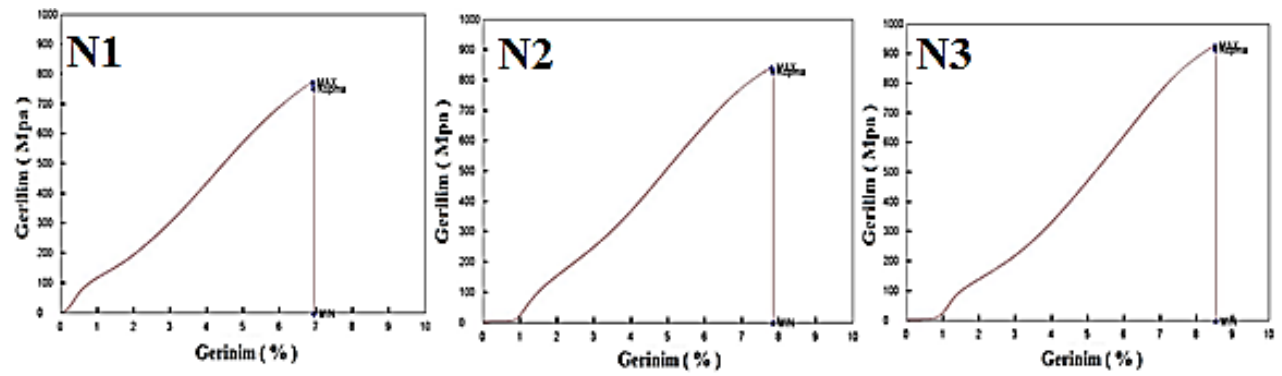

Şekil 12. Kaynaklı birleştirmelere ait gerilim-gerinim grafikleri

Tablo 6. Çekme Testi yapılan numunelerin max. çekme, kopma gerilme ve \% gerinim değerleri

\begin{tabular}{|c|c|c|c|c|c|c|c|}
\hline $\begin{array}{l}\text { NUMUNE } \\
\text { NO }\end{array}$ & Akım & $\begin{array}{l}\text { Gerilim } \\
\text { (Volt) }\end{array}$ & $\begin{array}{l}\text { Tel İler. Hizı } \\
\text { (cm/dk.) }\end{array}$ & $\begin{array}{l}\text { Çekme } \\
\text { İler. Hızı } \\
(\mathbf{m m} / \mathbf{d k})\end{array}$ & $\begin{array}{l}\text { Max. Çekme } \\
\text { Gerilimi } \\
\text { ( MPa ) }\end{array}$ & $\begin{array}{l}\begin{array}{l}\text { Kopma } \\
\text { Gerilimi } \\
\text { ( MPa ) }\end{array} \\
\end{array}$ & Gerinim (\%) \\
\hline N1 & & & 20 & & 768.924 & 749.880 & 6.91 \\
\hline N2 & 250 & 25 & 25 & 1 & 838.278 & 826.011 & 7.81 \\
\hline N3 & & & 30 & & 923.224 & 911.777 & 8.51 \\
\hline
\end{tabular}

Kaynaklı birleștirmelerde sabit 250 A ve 25 volt geriliminde kaynak tel ilerleme hızı arttıkça kaynak metalindeki max. çekme ve kopma gerilimleri ve buna bağlı olarak \% gerinimler artmaktadır. Nüfuziyetin tam sağlanmasından dolay1 kopma, kaynak metalinin tam ortasinda gerçekleşmiştir. Sünek kırılmayı Ramor 500 çelik çiftlerinin kopma yüzeylerinden alınan Şekil 13 'de görüldüğü gibi kırık kopma yüzey SEM-
XRD analizleri incelendiğinde gözlemlenir. Kırık yüzey süngerimsi, lifli pürüzlü yapıda sünek kırılma mekanizmasına uygun şekilde bir yapıya sahiptir. Kırık yüzeyler sürekli uygulanan gerilme altında yapısal düzensizliklerin kaynak dikişi merkezine doğru ilerlemesi yani uygulanan kuvvete dik doğrultuda çatlağın ilerlemesi mekanizmasıyla kopar (Yiğittürk, 2016). 
Şekil 13. Kaynaklı birleștirmelerin kırık kopma yüzeyinin SEMXRD analizleri
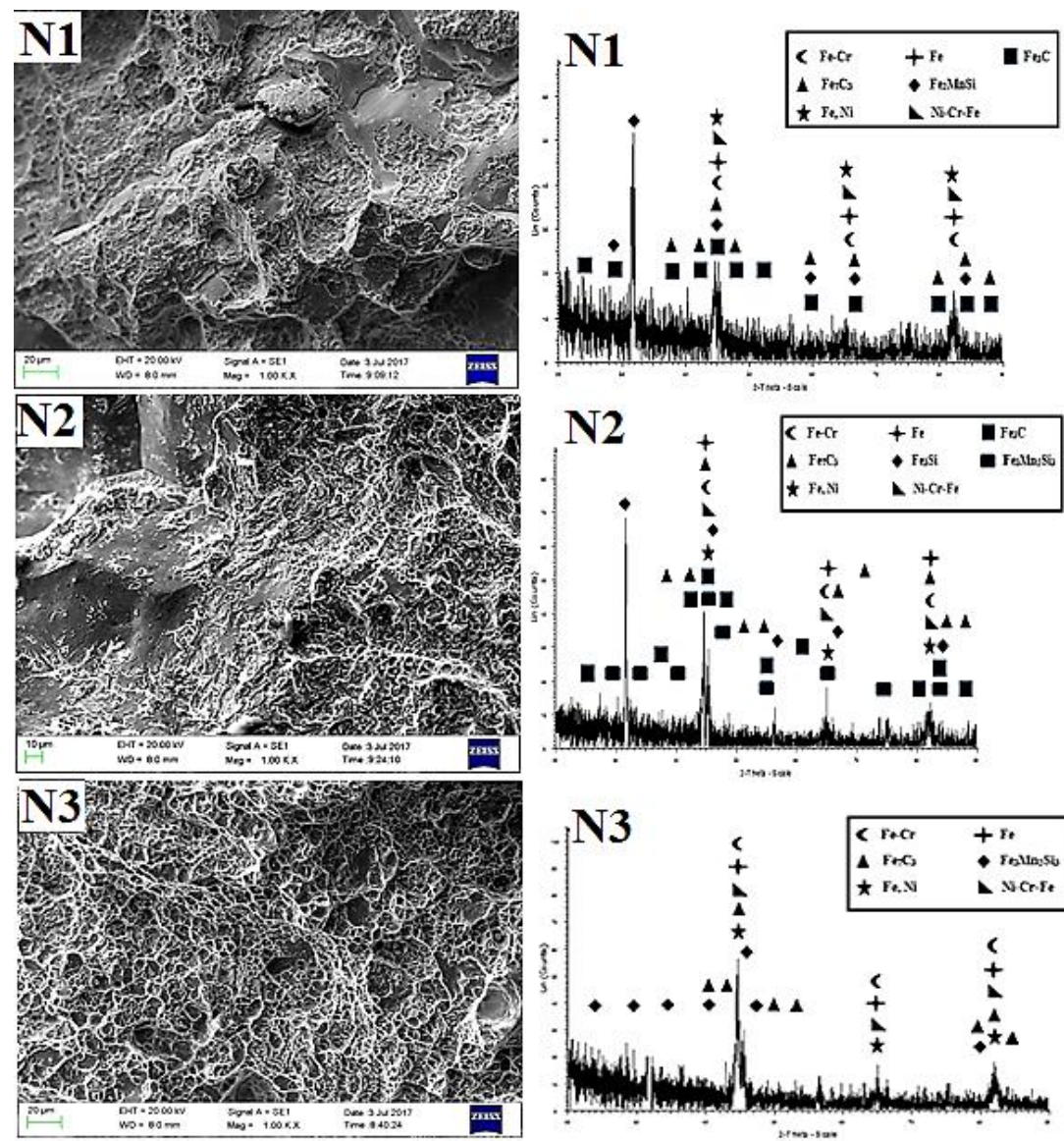

Şekil 13'deki XRD analiz sonuçları incelendiğinde, ana malzeme ile ilave telin kimyasal yapılarından dolay1 $\mathrm{Fe}-\mathrm{Cr}, \mathrm{Fe}_{7} \mathrm{C}_{3}, \mathrm{Fe}_{3} \mathrm{C}$, $\mathrm{Ni}-\mathrm{Cr}-\mathrm{Fe}$ gibi sert karbür bileşikleri oluşmuştur. Östenitik paslanmaz çeliklerin kaynağında, krom karbür oluşumu; kaynaklı malzemelerde ITAB bölgesinde $\left(430-870^{\circ} \mathrm{C}\right)$ arasında yapıdaki $\mathrm{Cr}$ tane sınırlarına doğru yerleşir ve bu bölgesel alanlarda (ITAB), Cr zayıflayacağı için korozyon dayanımı düşer (Yiğittürk, 2016). Dolayısıyla Cr-Ni-Mn esaslı ilave östenitik esaslı çelik tel kullanılarak yüksek mukavemet sağlayan kaynak dikişi elde edilmiş olur.

\section{Sonuçlar}

Ramor 500 zır çeliği çiftleri sabit amper, sabit gerilim ve farklı ilerleme hızları kullanılarak Tozaltı kaynak yöntemiyle birleştirilmiştir. Elde edilen sonuçlar aşağıda verilmiştir.

$250 \mathrm{~A}^{\prime}$ de 25 volt geriliminde, 20, 25, 30 $\mathrm{cm} / \mathrm{dk}$ sabit tel ilerleme hizlarında birleștirilen N1, N2 ve N3 numunelerinde radyografik muayenede uluslararası kaynak enstitüsünün yayınladığı ilkelere göre (Yıldız vd., 2017; Çalıgülü vd., 2016; Gür vd., 2016), N1 numunesinde kaynağın bitiş bölgesinde çok küçük oranda E (çatlak), N2 numunesinde A Kabul) raporu, N3 numunesinde ise kaynağın başlangıç ve bitiş bölgelerinde çok küçük oranda Dc (nüfuziyet noksanlığı) hataları gözlemlenmiştir.

$>$ Mikrosertlik analizler sonuçlarının tamamında elde edilen sertlik eğrilerine göre karşılaştırıldığında, kaynak dikişlerinin sertliğinde, ana malzeme olan Ramor 500 çelik çiftlerine göre artış gözlemlenmiştir.

$>$ XRD analiz sonuçları incelendiğinde, ana malzeme ile ilave telin kimyasal yapılarından dolay1 $\mathrm{Fe}-\mathrm{Cr}, \mathrm{Fe}_{7} \mathrm{C}_{3}, \mathrm{Fe}_{3} \mathrm{C}$, Ni-Cr-Fe gibi sert karbür bileşikleri oluşmuştur.

$>$ Kaynaklı birleştirmelerde sabit 250 A ve 25 volt geriliminde kaynak tel ilerleme hizı arttıkça kaynak metalindeki max. çekme ve kopma gerilimleri ve buna bağlı olarak \% gerinimler artmaktadır. Nüfuziyetin tam sağlanmasından dolayı kopma, kaynak metalinin tam ortasından gerçekleşmiştir.

> Kaynaklı birleştirmelere uygulanan çekme testi sonucunda kopan numunelerin ölçüm değerleri incelendiğinde boyun vermeden kırılma meydana geldiği gözlemlenmiştir. Dolayısıyla bu haliyle incelenen çelik malzemenin boyun vermemiş olması her ne kadar gevrek malzemeymiş gibi görünse de, makro görüntüler incelendiğinde kopma yüzeylerinde koni-çanak yapılarını andıran 
görüntüler vardır. Ayrıca kopma yüzeyleri tam düz değil tırtırlı olacak şekilde kopmuştur ve yapılar SEM-XRD analizlerinden elde edilen sonuçlarla sünek kırılma şeklinde tespit edilmiştir.

> Kaynak işlemi uygulandıktan sonra ana malzeme çiftinin olduğu bölgelerde, sertlikte çeliğin işlem görmemiş değerine göre azalma, ITAB bölgesinde sicaklığın etkisiyle tane yapılarında büyüme ve sertlikte azalma ve sonra kaynak metaline doğru artış görülmüştür.

Kaynaklı birleştirmelerin kaynak dikiş̧ geometrisi üzerindeki etkisi kaynak tel ilerleme hızı arttıkça ters orantılı olarak kaynak genişlik ve yüksekliği azalmıştır. Kaynak hızı yükseldikçe, nüfuziyet ile dikiş genişliğinin azaldığı görülür. Kaynak hızının artması, dikişlerin daha dikkatli kaynak edilmesini gerektirir. Gereğinden fazla kaynak hızı, ark üflemesini, gözeneği ve çatlağı arttırır, dikişin şeklini bozar (Akkaş, 2006).

\section{Teşekkür}

Bu çalışma Fırat Üniversitesi Bilimsel Araştırma Projeleri (FÜBAP) birimi tarafindan TEKF. 16.24 numaralı proje kapsamında desteklenmiştir.

\section{Kaynaklar}

Akkaş N., 2006. Tozaltı Köşe Kaynağında Yapay Zekâ Teknolojileri Kullanılarak Dikiş Geometrisinin Modellenmesi. Sakarya Üniversitesi Fen Bilimleri Enstitüsü, Makina Mühendisliği, Yüksek Lisans Tezi, Sakarya.

Albayrak, M., 1997. The Control and Inspection of the Welding Seams. Igdas.

Atapek H., 2011. Bor katkılı bir zırh çeliğinin fiziksel metalurjik esaslar doğrultusunda geliştirilmesi ve balistik performansının değerlendirilmesi, Doktora tezi, Kocaeli Üniversitesi Fen Bilimleri Enstitüsü, Kocaeli.

Aydemir, B., 2013. Metalik Malzemelerin Çekme Deney Standardı EN ISO 6892-1'in Getirdiği Değişiklikler. Makine Teknolojileri Elektronik Dergisi , 10 (3), 61-70.

Çalıgülü, U., Açık, M., Türkmen M. ve Gür, A.K., 2016. Radiography Test of AISI 1010-Copper Alloys Welded by Friction Welding. Sylwan, 160 (4), 468-479.

Dedehayır, F., 1985. Tanklarda Kullanılan Zurh Çeliklerinin Kaynak Kabiliyetinin Etüd Doktora
Tezi, Erciyes Üniversitesi Fen Bilimleri Enstitüsü, Kayseri.

Durgutlu, A., Gülenç, B. ve Tülbentçi, K., 1999. Ark Kaynağında Kaynak Hızının Nüfuziyete ve Mikroyapıya Etkisi. Tr. J. of Engineering and Environmental Science, 23, 251-259.

Gunaraj, N. ve Murugan, V., 1999. Prediction and comparison of the area of the heat-affected zone for the bead-on-plate and bead-on-joint in submerged arc welding of pipes. Journal of Materials Processing Technology, 95, 246-261.

Gür, A.K., Yigittürk, N. ve Yildı, T., 2016. Examination Of Welding Characteristics Of AISI304-Ramor 500 Steel Couples Welded By Plasma Transferred Arc Welding. Sylwan, 160 (11), 212-225.

Kaluç, E., 2004. Ergitme Esaslı Kaynak Yöntemleri, Kaynak Teknolojisi El Kitabı. Cilt 1: Makine Mühendisleri Odası Kocaeli Şubesi, Yayın No: 975- 395- 739- 4.

Karagöz, Ş., Atapek, Ş.H. ve Yılmaz A., 2008. Zırh çeliklerinde perforasyon ve balistik korumanın anlaşılması açısından fragtografik etüd. Metal Dünyası, 182, 102-107.

Maweja, W.S.K., 2006. Fracture and Ballistic induced phase transformation in tempered martensitic low-carbon armour steels. Materials Science and engineering A, 432, 158-169.

Memiş, İ., 2016. Impact Response Of Ramor 500 Armor Impact Response Of Ramor 500 Armor Steel Subjected To High Velocities. Graduate School of Natural and Applied Science of Dokuz Eylül University In Partial Fullfilment of the Requirements for the Master of Science of Mechanical Engineering, Mechanic Program, İzmir.

Özakın, N., 2010. AH ve DH kalite gemi saclarının değişik kaynak yöntemleri ve kaynak pozisyonlarındaki mekanik özelliklerinin ve mikroyapılarının iredelenmesi. Yüksek Lisans Tezi, Zonguldak Karaelmas Üniversitesi Fen Bilimleri Enstitüsü, Zonguldak.

Soykan, Y., Aslanoğlu, H. Ş., ve Karakaş, Z., 2005. Zırh Çeliklerinin Metalurjisi Erdemir Semineri.

Taşkaya, S, Yıldız, T. ve Gür, A.K., 2018. The Effect of Voltage on Joining of Ramor 500 Armor Steel With Submerged Arc Welding Method. Sakarya University Journal of Science, 22 (2), 357-363

Taşkaya, S., 2017. Ramor 500 Çeliğinin Tozalti Kaynağiyla Birleştirilmesi ve Ansys Paket Programiyla Değerlendirilmesi. Firat 
Üniversitesi. Fen Bilimleri Enstitüsü, Metalurji ve Malzeme Mühendisliği A.B.D., Elazığ.

TB9-2330-224-50/1, 1969. Procedures for repairar of combotolomeged hulls and Turrets 16 July. Department of the Army Technical Bulletin, 1, 155-165.

Tekiz, T., 1984.The Non-destructive Testings, ITU Faculty of Mechanical Engineering, Istanbul.

TS EN 444, 1994.TS EN 462 Standards.

Wikle Iii, B. A., Kottilingam, H.C., Zee, S. ve Chin, R.H., 2001. Infrared sensing techniques for penetration depth control of the submerged arc welding process. Journal of Materials Processing Technology, 113, 228-233.

Y1ld1z, T., Gür, A.K. ve Bilen, F.A., 2017. The Investigation of Welding Availability Of AISI304-Hardox 400 Steel Couples Welded By Plasma Transferred Arc Welding. Ciência e Técnica Vitivinícola Journal, 32 (10), 190-204.
Yiğittürk, N., 2016. Ramor Zırh Çeliği İle AISI 304 Paslanmaz Çelik Çiftlerinin Plazma Transferli Ark Kaynak Yöntemi İle Birleştirilebilirliğinin Araştırılması. Fırat Üniversitesi Fen Bilimleri Enstitüsü, Metalurji ve Malzeme Mühendisliği A.B.D., Elazığ.

URL-1, The Collaboration for NDT Education, http://www.ndt-ed.org . 12 May1s 2018.

URL-2, ODTÜ Kaynak Teknolojisi ve Tahribatsız Muayene Araştırma/ Uygulama Merkezi, http://www.wtndt.metu.edu.tr . 16 Mayıs 2018.

URL-3,SSAB,http://www.ssab.com.tr/products/brands/ armox/armox-500t . 09 Mayis 2018.

URL-4, Oerlikon Kaynak Elektrodları ve Sanayi A.Ş., http://www.oerlikon.com.tr . 17 Mayıs 2018.

URL-5,

http://www.esabna.com/EUWeb/SA_handbook/ 585sa1_1.htm . 20 Mayıs 2018. 